\title{
Fast Rigorous Analysis of Rectangular Waveguides by Optimized 2D-TLM
}

\author{
Ayhan Akbal and Hasan H. Balik \\ University of Firat, Department of Electrical and Electronics Engineering, Elazig, Turkey \\ ayhanakbal@gmail.com, hasanbalik@gmail.com
}

\begin{abstract}
In this paper, The optimized 2D-TLM as been introduced and applied to rectangular waveguides which is widely used. Results obtained by using optimized 2D-TLM were compared with analytic results and shown to be accurate.
\end{abstract}

\section{Introduction}

Rectangular waveguide is one of the earliest type of the transmission lines and still commonly used in many current applications. A lot of components such as isolators, detectors, attenuators, couplers and slotted lines are available to use for various standard waveguide bands between $1 \mathrm{GHz}$ to above $220 \mathrm{GHz}$ [1]. At the operating frequencies where these waveguides commonly used, the assumptions which are valid only low frequencies can not be applied to gain accurate results. Therefore full-wave analysis techniques must be required. Some of these full-wave numerical techniques solve the problem in time domain [2-4] whereas others solve in frequency domain [47]. Although full-wave numerical technique gives accurate results, it requires more time and computer resources for solutions. The demands of the design engineer require a technique which is accurate, yet retains the interactive design capabilities of the simpler techniques.

In this contribution, time and frequency domain analysis of rectangular waveguide has been accurately analyzed by enhanced 2-D TLM method and shown to be accurate to find mode cut-off frequency.

\section{Review to Rectangular Waveguides}

The rectangular waveguide shown in Fig. 1 supports both TM and TE modes; therefore it is not possible to define unique voltage by only using TEM waves at the recent operating frequencies. The waves cannot propagate trough the rectangular waveguide if the operating frequency is below then some certain frequency. This frequency is called cut-off frequency. The mode frequency must be higher then this cut-off frequency. If mode frequency is lower then cut-off frequency, propagating waves decay rapidly in the direction of waveguides axes. When the operating frequency is higher then cut-off frequency, waves have two modes. These are TE and TM modes respectively. The cut-off frequency has been only determined by geometry of the wave guides. 

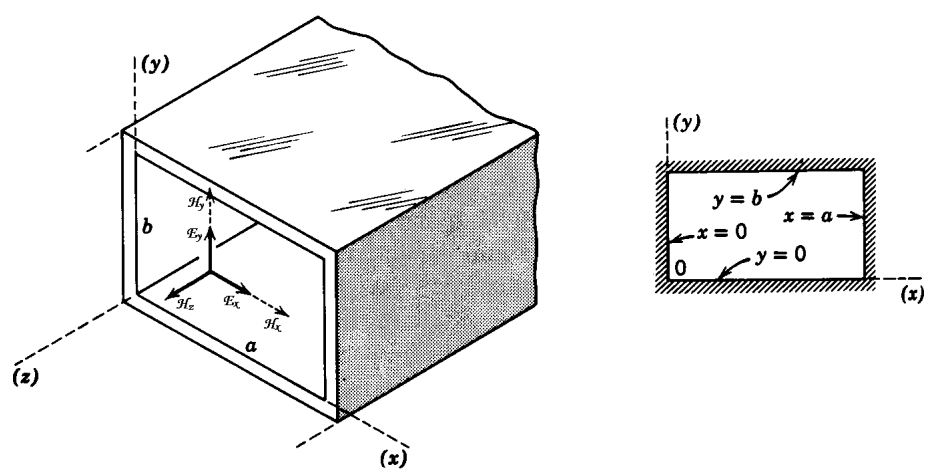

Fig. 1. Rectangular Waveguides

Mode cut-off frequency can be analytically calculated by;

$$
\mathrm{f}_{\mathrm{c}, \mathrm{mn}}=\frac{1}{2 \pi \sqrt{\mu \varepsilon}} \sqrt{\left(\frac{\mathrm{m} \pi}{\mathrm{a}}\right)^{2}+\left(\frac{\mathrm{n} \pi}{\mathrm{b}}\right)^{2}}
$$

where $\mathrm{m}$ and $\mathrm{n}$ are mode degrees respectively.

\section{Optimized 2D-TLM Method}

TLM was first introduced by P. N. John in 1970. This technique is based on the field theory - the circuit theory similarities. Transmission line modeling divides the structure into unit cells and structure model is carried out by solving each cell

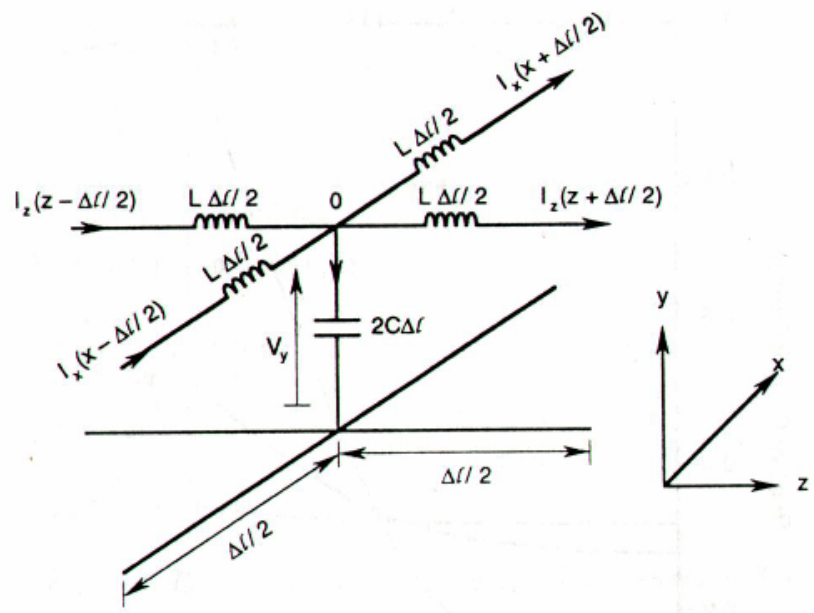

Fig. 2. Two Dimensional TLM Cell 
separately. Current and voltage are set to be independent variables. The correlation between input and output voltage is found by applying Kirchoff current and voltage laws onto Fig. 2 which is circuit model of the cell analyzed.

TLM method like FDTD is interested in Maxwell equations. Given microwave structure which is rectangular waveguide in this application has been divided into cells. Each cell has been traded as electrical circuit and therefore electrical circuit solution has been applied onto the every cell repeatedly. The main advantage of TLM against MoM or SDM, TDM does not require any pre-calculation. As a result of this advantage, any optimization can be applied to any microwave circuits without refinements. Another reason to choose TLM for this contribution is that TLM method is very easy to adapt on the computer programming.

2D-TLM Equation is given by;

$$
\frac{\partial^{2} \Phi}{\partial u^{2}}+\frac{\partial^{2} \Phi}{\partial v^{2}}=\mu \varepsilon \frac{\partial^{2} \Phi}{\partial t^{2}}
$$

For $2 \mathrm{D}$ applications $\frac{\partial}{\partial y}=0$ and $\mathrm{E}_{\mathrm{x}}=\mathrm{E}_{\mathrm{y}}=\mathrm{H}_{\mathrm{y}}=0$. Therefore;

$$
\begin{gathered}
\frac{\partial H_{x}}{\partial z}-\frac{\partial H_{z}}{\partial x}=+\varepsilon \frac{\partial E_{y}}{\partial t} \\
\frac{\partial^{2} E_{y}}{\partial x^{2}}+\frac{\partial^{2} E_{y}}{\partial z^{2}}=\mu \varepsilon \frac{\partial^{2} E_{y}}{\partial t^{2}}
\end{gathered}
$$

Both equation (3) and equation (4) are very similar. If above equations are rewritten as voltage and current;

$$
\begin{gathered}
E_{y} \equiv V_{y}, \quad H_{z} \equiv I_{x}, H_{x} \equiv-I_{z}, \mu=L, \quad \varepsilon=2 C \\
\mu_{r}=\varepsilon_{r}=1 \text { and } 1 / \sqrt{L C}=1 / \sqrt{\mu_{0} \varepsilon_{0}}=c
\end{gathered}
$$

can be easily found. $\mathrm{c}$ is free space light speed in Equation (6).

\section{Computer Simulation and Numerical Results}

First analyzed mode and then maximum frequency of the interest must be determined. Because this process is necessary to specify time step and cell size of TLM simulation. To avoid numerical dispersion, the ratio of minimum wavelength and cell must be chosen carefully. Rectangular waveguide analyzed by TLM has divided into $\mathrm{N}_{\mathrm{x}} \mathrm{xN}_{\mathrm{y}}$ number of cells so that $\Delta \mathrm{x}$ and $\Delta \mathrm{y}$ are cell sizes in $\mathrm{x}-\mathrm{y}$ axes 
respectively. As a source, Gauss pulse of which durations have been chosen according to maximum operating frequency used. Gauss pulse is applied at one point, and the calculated field's components of observation points are saved. The frequency response of rectangular waveguides has been derived from the time response.

\subsection{TM Mode Analysis Results}

The analyzed rectangular waveguide's dimensions are given $90 \mathrm{~mm}$ in width and $45 \mathrm{~mm}$ in height respectively. Chosen parameters used throughout the computer simulation of TM Mode by optimized TLM technique are given in Table 1

Table 1. 2D-TLM Parameters for TM Modes

\begin{tabular}{lc}
\hline $\mathrm{f}_{\max }$ (maximum frequency) & $10 \mathrm{GHz}$ \\
\hline$\Delta \mathrm{x}$ (cell size in $\mathrm{x}$-axes) & $1.125 \mathrm{~mm}$ \\
$\Delta \mathrm{y}$ (cell size in y-axes) & $1.125 \mathrm{~mm}$ \\
$\mathrm{~N}_{\mathrm{x}}$ (number of cell in x-axes) & 80 \\
$\mathrm{~N}_{\mathrm{y}}$ (number of cell in y-axes) & 40 \\
$\Delta \mathrm{t}$ (time step) & 2.76 pico second \\
$\mathrm{T}$ (simulation duration) & $10000 \Delta \mathrm{t}$ \\
$\Delta \mathrm{f}$ (frequency resolution) & $36.23 \mathrm{MHz}$ \\
\hline
\end{tabular}

Table 2 compares optimized results and analytical results. It is demonstrated that optimized TLM algorithm presented here has good agreement with analytical results and error is less then $0.2 \%$. Time and frequency response of TM modes are given in Figure 3.

Table 2. 2D-TLM Simulation Results and Analytic Result TM Modes Frequencies

\begin{tabular}{|c|c|c|c|}
\hline & Analytical Results (GHz) & TLM Results (GHz) & Error \\
\hline$T M_{11}$ & 3.7268 & 3,6978 & $\mathbf{0 , 0 2 9 0}$ \\
\hline $\mathbf{T} \mathbf{M}_{21}$ & 4.7140 & 4,6994 & 0,0146 \\
\hline $\mathbf{T M}_{31}$ & 6.0093 & 5,9869 & 0,0224 \\
\hline $\mathrm{TM}_{12}$ & 6.8718 & 6,8703 & 0,0015 \\
\hline $\mathbf{T M}_{22} \mathbf{T M}_{41}$ & 7.4536 & 7,4155 & $\mathbf{0 , 0 3 8 1}$ \\
\hline $\mathrm{TM}_{32}$ & 8.3333 & 8,3150 & $\mathbf{0 , 0 1 8 3}$ \\
\hline $\mathbf{T M}_{51}$ & 8.9753 & 8,9279 & 0,0474 \\
\hline $\mathbf{T M}_{42}$ & 9.4281 & 9,4059 & $\mathbf{0 , 0 2 2 2}$ \\
\hline
\end{tabular}

\subsection{TE Mode Analysis Results}

Chosen parameters used throughout the computer simulation of TE Mode by optimized TLM technique are given in Table 3. 

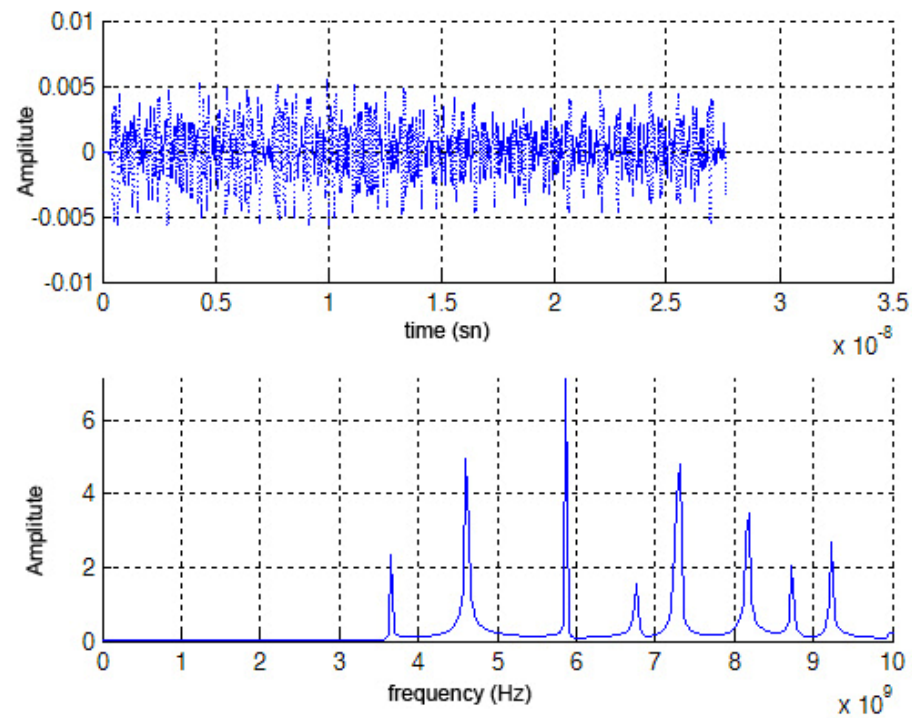

Fig. 3. TM Mode Time and Frequencies Response

Table 3. 2D-TLM Parameters for TE Modes

\begin{tabular}{lc}
\hline $\mathrm{f}_{\max }$ (maximum frequency) & $10 \mathrm{GHz}$ \\
\hline$\Delta \mathrm{x}$ (cell size in $\mathrm{x}$-axes) & $2.25 \mathrm{~mm}$ \\
$\Delta \mathrm{y}$ (cell size in y-axes) & $2.25 \mathrm{~mm}$ \\
$\mathrm{~N}_{\mathrm{x}}$ (number of cell in x-axes) & 40 \\
$\mathrm{~N}_{\mathrm{y}}$ (number of cell in y-axes) & 20 \\
$\Delta \mathrm{t}$ (time step) & 5.46 pico second \\
$\mathrm{T}$ (simulation duration) & $10000 \Delta \mathrm{t}$ \\
$\Delta \mathrm{f}$ (frequency resolution) & $18.31 \mathrm{MHz}$ \\
\hline
\end{tabular}

Table 4. 2D-TLM Simulation Results and Analytic Result TE Modes Frequencies

\begin{tabular}{cccc}
\hline & Analytical Results $(\mathrm{GHz})$ & TLM Results $(\mathrm{GHz})$ & Error \\
\hline $\mathrm{TE}_{10}$ & 1.6667 & 1.6476 & 0,0191 \\
$\mathrm{TE}_{01}$ ve $\mathrm{TE}_{20}$ & 3.3333 & 3.2962 & 0,0371 \\
$\mathrm{TE}_{11}$ & 3.7268 & 3.6980 & 0,0288 \\
$\mathrm{TE}_{21}$ & 4.7140 & 4.9001 & $-0,1861$ \\
$\mathrm{TE}_{30}$ & 5.0000 & 4.9866 & 0,0134 \\
$\mathrm{TE}_{31}$ & 6.0093 & 5.9670 & 0,0423 \\
$\mathrm{TE}_{40}$ ve $\mathrm{TE}_{02}$ & 6.6667 & 6.5540 & 0,1127 \\
$\mathrm{TE}_{12}$ & 6.8718 & 6.8130 & 0,0588 \\
$\mathrm{TE}_{41}$ ve $\mathrm{TE}_{22}$ & 7.4536 & 7.3594 & 0,0942 \\
$\mathrm{TE}_{50}$ ve $\mathrm{TE}_{32}$ & 8.3333 & 8.2039 & 0,1294 \\
$\mathrm{TE}_{51}$ & 8.9753 & 8.8240 & 0,1513 \\
$\mathrm{TE}_{42}$ & 9.4281 & 9.4002 & 0,0279 \\
\hline
\end{tabular}


Table 4 compares optimized results and analytical results. It is demonstrated that optimized TLM algorithm presented here has a good agreement with analytical results and error is less then $0.2 \%$. Time and frequency response of TE modes are given in Figure 4.
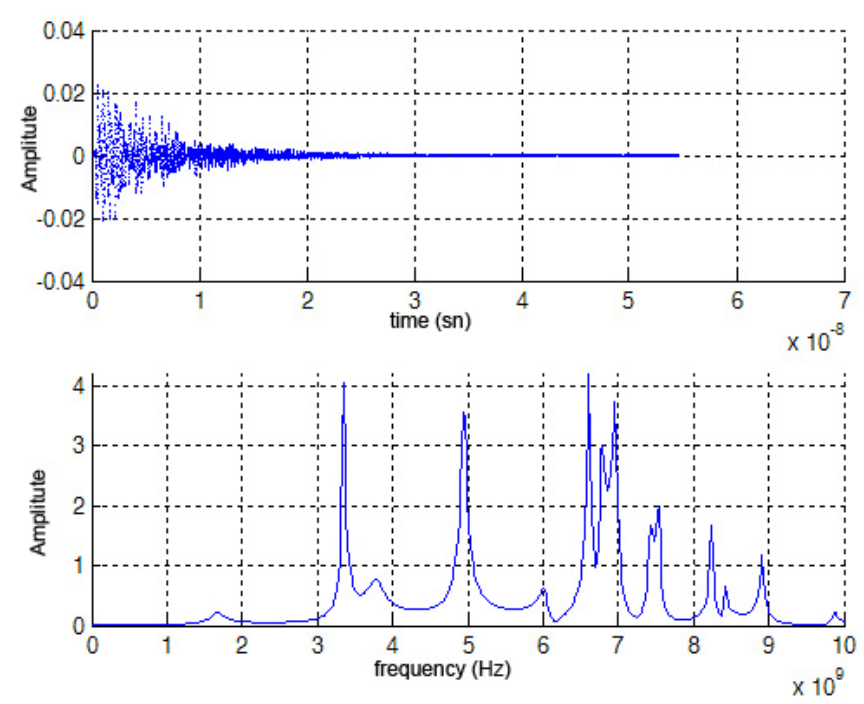

Fig. 4. TE Mode Time and Frequencies Response

\section{Conclusion}

In this paper, optimized 2D-TLM method has been introduced to analyze widely used rectangular waveguides. It is found and demonstrated in this contribution that the results are in very good agreements to analytical results.

\section{References}

[1] D.M. Pozar, Microwave Engineering, USA, 1998.

[2] K. L.Tsakmakidis, C. Hermann, A. Klaedtke, C. Jamois, O. Hess, "Systematic Modal Analysis of 3-D Dielectric Waveguides Using Conventional and High Accuracy Nonstandard FDTD Algorithms", IEEE Photonics Technology Letters, 17(12), pp 2598 2600, Dec.2005.

[3] J. Hesselbarth and R. Vahldieck, "Resonance frequencies calculated efficiently with the frequency-domain TLM method," Microwave and Wireless Components Letters, vol. 13, pp. 190 - 192, May 2003.

[4] Kreczkowski and M. Mrozowski, "Efficient multimode mixed time-frequency domain analysis and optimization of waveguide structures," Microwaves, Radar and Wireless Communications, Vol. 3, pp. 803 - 806, May 2004. 
[5] Hasan H. Balik and C. J. Railton, New Compensation Functions for Efficient Excitation of Open Planar Circuits in SDM , IEEE Trans. On Microwave Theory and Technique , 47 , 106-108 , Jan 1999

[6] I.A. Eshrah, A.A. Kishk, A.B. Yakovlev and A.W. Glisson, "Spectral Analysis of LeftHanded Rectangular Waveguides With Dielectric-Filled Corrugations," Antennas and Propagation, vol. 53, pp. 3673 - 3683, Nov. 2005.

[7] Hasan H. Balik, Final Remedy of the Excitation in the Analysis of Open Planar Circuits , International Journal for Engineering Modelling, Vol. 16, No. 3-4 , 99-103 , 2003. 